\title{
Drug-dispensing limits within Medicaid during the COVID-19 pandemic
}

\section{SUMMARY}

The 1-month drug-dispensing limit is a common drug utilization tool used by state Medicaid agencies to control spending. Since the beginning of the COVID-19 pandemic, many states relaxed the 1-month dispensing limit restriction in order to align with social distancing recommendations. Yet, some states have not relaxed this limit and have differed substantially regarding the policies that have been implemented. Among states that relaxed the 1-month supply limit, determining which chronic disease

Social distancing recommendations stemming from the COVID-19 pandemic-including limits to in-person trips to the pharmacy-are at odds with state Medicaid policies that limit the maximum allowable supply of prescription drugs to 1 month. Medicaid is the primary safety-net health insurance program for low-income Americans, many of whom, due to structural racism and inequity, ${ }^{1-3}$ have chronic illnesses that predispose them to worse COVID-19-related outcomes. As SARS-CoV-2 continues to spread at high levels across the United States, drug-dispensing policies that result in limited supplies of chronic medications for populations at high risk for severe COVID-19 disease should be reexamined.

The 1-month drug-dispensing limit among Medicaid beneficiaries dates back to the origins of Medicaid-passed drugs qualified for this extension can be challenging for patients and clinicians. As more commercial and Medicare insurance beneficiaries are offered 90 -day drug supplies, the 30-day drug supply limit with Medicaid has become a health equity issue, since many individuals insured by Medicaid have already experienced a disproportionate impact from and remain at high risk for severe COVID-19 disease. Thus, we propose policy solutions to ensure that Medicaid beneficiaries have safe and uninterrupted access to chronic disease medications during and beyond the COVID-19 pandemic. into law in 1965. In section 1927 of the Social Security Act, the federal government authorized states to "impose limitations... on the minimum or maximum quantities per prescription or on the number of refills, if such limitations are necessary to discourage waste, and may address instances of fraud or abuse." Since then, dispensing limits and other drug utilization strategies have become common tools within Medicaid to control spending caused by state budget strains from high prescription drug costs. Federal law requires that all drugs approved by the US Food and Drug Administration, with few exceptions, that are in the federal rebate program, be covered by state Medicaid programs. In 2018, Medicaid spent $\$ 61$ billion on prescription drugs, an increase of more than $89 \%$ over 10 years. ${ }^{5}$

\section{Author affiliations}

Jonathan D Alpern, MD, HealthPartners Institute, Minneapolis, MN, and Department of Medicine, University of Minnesota, Minneapolis. Nathan Chomilo, MD, Minnesota Department of Human Services, St. Paul, and Department of Pediatrics, University of Minnesota Medical School, Minneapolis. Malini Desilva, MD, MPH, HealthPartners Institute, Minneapolis, MN.

AUTHOR CORRESPONDENCE: Jonathan D Alpern, 207.712.2924; Jonathan.D.Alpern@HealthPartners.com

J Manag Care Spec Pharm. 2021;27(10):1489-93

Copyright $\odot 2021$, Academy of Managed Care Pharmacy. All rights reserved.

However, Medicaid's 1-month supply limit has come into question during the COVID-19 pandemic. The Centers for Disease Prevention and Control (CDC) recommends that individuals with underlying medical conditions have at least a 30-day supply of medications on hand and, if possible, more than 30 days of prescription medications in order to limit in-person visits to pharmacies. In March 2020, many states began relaxing their drug-dispensing limit restrictions by implementing an array of policy changes in alignment with CDC guidance. These policies vary substantially. For example, a few states increased the drug supply limit 
to 60 days (Michigan) or 68 days (Alaska), while most states relaxed the drug supply limit to 90 days. The types of drugs that have been granted these 90-day supply extensions range from "all noncontrolled substances" to "maintenance" drugs only, to more restrictive policies, such as in Illinois, which only considers insulin products as part of the 90-day supply rule (Table 1).

Even before the pandemic, many state Medicaid programs allowed 90-day supplies of certain maintenance drugs as exceptions to the 1-month supply limit. For example, Minnesota Medicaid's fee-for-service pharmacy program allowed 90-day supplies for common antihypertensive and lipid-lowering drugs. However, while these "maintenance drug lists" provide flexibility to beneficiaries who are prescribed drugs for chronic diseases, significant shortcomings have undercut their value. These lists are not always easily accessible to the public, making it difficult for patients and clinicians to determine whether a particular drug qualifies for a 90-day supply. Furthermore, maintenance drugs that are considered essential, such as HIV antiretroviral drugs, are often excluded from the maintenance drug lists. By contrast, most maintenance drugs prescribed to commercial insurance beneficiaries are for 90-day fills, likely reflecting patient preference as well as incentive structures in place (ie, levels of medication possession for patients) for pharmacies and accountable care organizations that steer patients towards 90-day fills. ${ }^{6}$

While individuals with commercial insurance are increasingly prescribed 90-day fills for chronic disease drugs, some Medicaid-insured patients continue to be limited to 1-month supplies during the COVID-19 pandemic. This creates a health equity issue, since SARS-CoV-2 infection rates continue to occur disproportionately among populations highly represented within Medicaid. Furthermore, Medicaid-insured patients are disproportionately reliant on public transportation to access health care, which potentially contributes to disparities associated with the 1-month drug supply limit. For these reasons, we believe that state Medicaid programs that have not relaxed the 1-month drug supply limit should do so immediately.

States that have authorized 90-day supplies for certain maintenance drugs could further improve their policies. For example, states could authorize a blanket 90-day drug supply extension for all noncontrolled substance drugs, removing uncertainty about whether a drug is considered "maintenance," and ensuring the inclusion of essential medications often prescribed for more than 30 days. This policy change would align with Medicare Part D policy under the Coronavirus Aid, Relief, and Economic Security Act, which requires Medicare Part D sponsors to suspend all drug supply limits under 90 days.? Alternatively, state pharmacy and therapeutics committees could expand the criteria for inclusion of drugs on the maintenance drug lists, ensuring incorporation of all chronic disease drugs that are noncontrolled substance-including drugs frequently omitted, such as antiretrovirals.

Since this change would require pharmacies to maintain a larger inventory of high-cost drugs, it could be implemented for select patients, such as those who have met certain adherence level measures. Because changes to Medicaid will have a disproportionate effect on Black, Indigenous, and other communities of color that have been disadvantaged due to structural racism, a racial equity lens should be applied as these policy changes are considered. ${ }^{8}$

Concerns about waste have driven the 1-month supply limit historically and are likely barriers to policy change. Although previous data have suggested no increase in the percentage of wastage days among Medicaid beneficiaries taking 90-day supplies compared with 30 days, ${ }^{9}$ early drug discontinuations before 90 days is a valid concern that would increase waste.

Concerns about increased cost associated with 90-day supplies are additional potential barriers to policy change. Since Medicaid is a counter-cyclical program (ie, economic downturns result in increased spending and lower revenues), the current recession has created greater demands on budgets, which states are mandated to keep balanced. Yet, there is little published data to suggest that 1-month drug supply limits lower cost within Medicaid. The data available suggest that a longer supply of drug therapy (90 days or 100 days), compared with 30 days, may result in cost savings to Medicaid. ${ }^{6,7}$ Whether the costs savings hold true for high-cost drugs, such as antiretrovirals, is unknown and should be a focus of future research.

Although most policies enacted in response to COVID-19 will end after the lifting of the national public health emergency declaration, the varied state approaches to relaxing drug supply limits during the pandemic may allow for experimentation that informs future policy beyond the pandemic. States could compare key outcomes-cost, waste, or adherence-among Medicaid beneficiaries prescribed $30 \mathrm{vs}$ 90 days of certain chronic disease medications to identify drugs in which a 90-day supply may be more appropriate and improve outcomes. For example, antimalarial medications are among the most widely prescribed medications and used as first-line agents for malaria prophylaxis. Their exclusion from the 90-day supply lists imposed by states causes access problems for Medicaid-insured patients traveling outside of the United States for more than 30 days. In this common scenario, patients inevitably deplete their supply of antimalarials during travel. The absence of medication after the 30 days is unsafe and may 


\section{TABLE 1 Policy Changes to Drug-Dispensing Limits in State Medicaid Programs During the COVID-19 Pandemic}

\begin{tabular}{|c|c|}
\hline State $^{a}$ & Policy change during COVID \\
\hline Alabama & $\begin{array}{l}\text { Pharmacists allowed to process emergency prescription refills for a } 30 \text {-day supply of maintenance medications under } \\
\text { certain circumstances. }{ }^{10}\end{array}$ \\
\hline Alaska & Allows 68-day fills on medications otherwise limited to a 34-day supply. ${ }^{11}$ \\
\hline Arizona & Allows "refill too soon" and 90-day refills for medications that are not controlled substances. ${ }^{12}$ \\
\hline Colorado & $\begin{array}{l}\text { Pharmacies can refill any prescription after } 50 \% \text { of the supply has lapsed. Maintenance medications can be dispensed } \\
\text { up to a maximum of } 100 \text {-day supply. Maximum allowed for nonmaintenance drugs is } 30 \text { days. }{ }^{13}\end{array}$ \\
\hline Connecticut & Extends fills for maintenance and nonmaintenance medications for noncontrolled substances up to 90 days. ${ }^{14}$ \\
\hline District of Columbia & $\begin{array}{l}\text { Allows a } 90 \text {-day supply for maintenance medications and 30-day supply for nonmaintenance medications among } \\
\text { fee-for-service beneficiaries only.15 }\end{array}$ \\
\hline Florida & $\begin{array}{l}\text { Will reimburse for a } 90 \text {-day supply of maintenance medications when available at the pharmacy or through mail order } \\
\text { delivery. }{ }^{16}\end{array}$ \\
\hline Georgia & $\begin{array}{l}\text { (1) Among fee-for-service beneficiaries, early refills waived on } 30 \text {-day prescriptions for maintenance medications at } \\
\text { in-network pharmacy; and ( } 2 \text { a a } 1 \text {-time } 90 \text {-day supply of a prescription medication is allowed if the member has no } \\
\text { remaining refills and the pharmacist cannot contact the practitioner. }{ }^{17}\end{array}$ \\
\hline lowa & Temporarily allows up to a 90-day supply for all medications, based on the clinical prescriber's judgment. ${ }^{18}$ \\
\hline Illinois & $\begin{array}{l}\text { Allows a } 90 \text {-day supply to be filled for insulin; reviewing potential additions to the } 90 \text {-day supply list of maintenance } \\
\text { medications. }{ }^{19}\end{array}$ \\
\hline Indiana & Allows 90-day supply of maintenance drugs upon member request and early refills for noncontrolled substances. ${ }^{20}$ \\
\hline Louisiana & Members may receive early refills and 90 -day supplies of certain maintenance medications, as appropriate. ${ }^{21}$ \\
\hline Maine & $\begin{array}{l}\text { Allows an additional 34-day refill for brand medications. Members already receive up to } 90 \text {-day supply of generic } \\
\text { medications. }{ }^{22}\end{array}$ \\
\hline Maryland & $\begin{array}{l}\text { For fee-for-service members, allows a 1-time early refill of at least a } 30 \text {-day supply of the participant's medication } \\
\text { (up to } 90 \text {-day supply for maintenance medication), before the participant uses } 85 \% \text { of the medication. }{ }^{23}\end{array}$ \\
\hline Massachusetts & Allows early refills and 90-day supplies of certain medications. ${ }^{24}$ \\
\hline Michigan & $\begin{array}{l}\text { Pharmacists may dispense emergency refills of up to a } 60 \text {-day supply of any noncontrolled maintenance medication } \\
\text { if "failure to refill the drug might interrupt the patient's ongoing care and have a significant adverse effect on the } \\
\text { patient's well-being." } 25\end{array}$ \\
\hline Minnesota & Increases the supply limit from 34-days to 90 days for drugs in certain therapeutic drug classes. ${ }^{26}$ \\
\hline New Hampshire & Allows a 1-time early refill override for current prescriptions. ${ }^{27}$ \\
\hline New Jersey & Allows early prescription refills and the dispensing of a 90-day supply of prescribed maintenance medications. ${ }^{28}$ \\
\hline New Mexico & $\begin{array}{l}\text { Allows 90-day supply for all maintenance drugs; early refills on 30-day prescriptions if member has } 2 \text { weeks of } \\
\text { medication on hand. Allows early refill on } 90 \text {-day prescription if member has } 3 \text { weeks of medication on hand. }{ }^{29}\end{array}$ \\
\hline New York & $\begin{array}{l}\text { Allows } 90 \text {-day supplies for long-term maintenance medications for individuals in quarantine, shelter in place, or those } \\
\text { identified as high risk for COVID-19. Early refills allowed for members in quarantine or in an "outbreak."30 }\end{array}$ \\
\hline North Carolina & Allows early refills and for coverage of up to a 90-day supply. ${ }^{31}$ \\
\hline North Dakota & May allow an increase of the supply limit from 34-days to a 1-time 90 -day fill. ${ }^{32}$ \\
\hline Virginia & $\begin{array}{l}\text { Covers a maximum of a } 90 \text {-day supply for all drugs excluding Schedule II drugs. A subsequent } 90 \text {-day supply will only be } \\
\text { allowed after } 75 \% \text { of the prescription has been used. }{ }^{33}\end{array}$ \\
\hline
\end{tabular}

exacerbate preexisting health disparities, since immigrant patients-many of whom receive their health insurance through Medicaid-frequently travel home for periods longer than 1 month to visit loved ones and are in the highest risk group for acquiring malaria.
As SARS-CoV-2 case numbers remain elevated and the emergence of COVID-19 variants threaten an already overwhelmed US health care system, policies are urgently needed to ensure social distancing and other basic public health measures, particularly among communities that 
are at high risk for severe disease. Ensuring uninterrupted and safe access to necessary medications for Medicaid beneficiaries during the COVID-19 pandemic should be urgently prioritized in order to limit the spread of COVID and its variants. In addition, after the pandemic, states should take advantage of opportunities to compare key outcomes between Medicaid beneficiaries prescribed 90-day vs 30-day supplies to determine if a 90-day drug supply is appropriate for certain medications covered by Medicaid.

\section{DISCLOSURES}

No funding was received for this work. Alpern has received funding from Arnold Ventures for research related to the use and spending of off-patent drugs, unrelated to this work, and is a member of the Pharmacy and Therapeutics Committee at Regions Hospital, St. Paul, MN. DeSilva has received CDC support for work on Vaccine Safety Datalink, VISION network, and Center of Excellence for Newcomer Health, unrelated to this work. Chomilo is Medicaid Medical Director for the State of Minnesota's Department of Human Services.

\section{REFERENCES}

1. Keet CA, Matsui EC, McCormack MC, Peng RD. Urban residence, neighborhood poverty, race/ethnicity, and asthma morbidity among children on Medicaid. J Allergy Clin Immunol. 2017;140:822-27.

2. Zhang S, Senteio C, Felizzola J, Rust G. Racial/ethnic disparities in antiretroviral treatment among HIV-infected pregnant Medicaid enrollees, 2005-2007. Am J Public Health. 2013;103:e46-53.

3. Horvitz-Lennon M, Volya R, Garfield R, Donohue JM, Lave JR, Normand SL. Where you live matters: quality and racial/ethnic disparities in schizophrenia care in four state Medicaid programs. Health Serv Res 2015;50(5):1710-29.
4. Social Security Administration. Compilation of the Social Security laws. Payment for Covered Outpatient Drugs. Sec. 1927. 42 USC 1396r-8. Accessed January 24, 2021. https://www.ssa.gov/ OP_Home/ssact/title19/1927.htm

5. Waldrop T, Calsyn M. State policy options to reduce prescription drug spending. Center for American Progress. February 13, 2020. Accessed January 24, 2021. https://www. americanprogress.org/issues/healthcare/reports/2020/02/13/480415/ state-policy-options-reduce-prescription-drug-spending/

6. IQVIA. Medicine use and spending in the U.S.: a review of 2018 and outlook to 2023. Institute report. May 9, 2019. Accessed January 24, 2021. https://www.iqvia.com/insights/ the-iqvia-institute/reports/ medicine-use-and-spending-in-the-us-areview-of-2018-and-outlook-to-2023

7. Centers for Medicare \& Medicaid Services. Information related to coronavirus disease 2019- COVID-19. May 22, 2020. Accessed January 24, 2021. https://www.cms.gov/files/document/ covid-19-updated-guidance-ma-and-partd-plan-sponsors-52220.pdf

8. Government Alliance on Race \& Equity. Tools \& resources. Accessed January 24, 2021. https://www.racialequityalliance. org/tools-resources/

9. Taitel M, Fensterheim L, Kirkham H, et al. Medication days' supply, adherence, wastage, and cost among chronic patients in Medicaid. Medicare Medicaid Res Rev. 2012;2(3):mmrr.002.03.a04.

10. Alabama Board of Pharmacy. Emergency prescription refills. March 23, 2020. Accessed January 30, 2021. alabamapublichealth.gov/legal/assets/ order-prescriptionrefills-032320.pdf

11. The State of Alaska, Department of Health and Human Services. COVID-19 preparedness-Alaska Medicaid pharmacy update 4/1/2020. April 1, 2020. Accessed January 30, 2021. http:// manuals.medicaidalaska.com/docs/dnld/ Update_Medicaid_Pharmacy_COVID19 20200401.pdf
12. Arizona Health Care Cost Containment System. Frequently asked questions regarding coronavirus disease 2019. Accessed January 30, 2021. https://www. azahcccs.gov/AHCCCS/AboutUs/covid19FAQ.html\#PharmacySupp

13. Colorado Department of Health Care Policy and Financing. Letter. Accessed January 30, 2021. https://www.colorado.gov/pacific/sites/default/files/ COVID-19\%20Guidance\%20for\%20 Prescribers\%2003-20-2020.pdf

14. Community Health Center Association of Connecticut. HUSKY health updates re: COVID-19. March 23, 2020. Accessed January 30, 2021. https://www.chcact.org/2020/03/23/ husky-health-updates-re-covid-19/

15. Government of the District of Columbia. Department of Health Care Finance. Novel coronavirus 2019: emergency authorization of a 90-day supply for maintenance medications and 30-day supply for non-maintenance medications. March 20, 2020. Accessed January 30, 2021. https://provider.amerigroup.com/ dam/publicdocuments/DCDC_CAID_ PU Pharm9030DayRXDispensEmergAuth. $\mathrm{pdf} ? \mathrm{v}=202101082012$

16. Florida Medicaid. Florida Medicaid health care alert. March 16, 2020. Accessed January 30, 2021. https:// ahca.myflorida.com/Medicaid/pdffiles/provider_alerts/2020_03/ Medicaid Coverage During SOE COVID-19 20200316.pdf

17. Georgia Department of Community Health. ATTN: Georgia Medicaid prescribers and pharmacy providers. Accessed January 30, 2021. https://medicaid. georgia.gov/document/document/ pharmacybannermessagepdf/download

18. Iowa Department of Human Services. Update to billing services related to coronavirus and COVID-19. March 19, 2020. Accessed January 30, 2021. https://dhs.iowa.gov/sites/default/ files/2119-MC-FFS-CVD_Telehealth_ and_Pharmacy_Billing_COVID19_2. pdf?081120210408 
19. Illinois Department of Healthcare and Family Services. Pharmacy - Temporary COVID-19 billing policies. March 30, 2020. Accessed January 30, 2021. https:// www.illinois.gov/hfs/MedicalProviders/ notices/Pages/prn200330a.aspx

20. Indiana Health Coverage Programs. Changes made to pharmacy supply limits and early refills. March 19, 2020. Accessed January 30, 2021. http:// provider.indianamedicaid.com/ihcp/ Bulletins/BT202021.pdf

21. Louisiana Department of Health. Novel coronavirus disease provider update. March 17, 2020. Accessed January 30, 2021. https://ldh.la.gov/assets/medicaid/COVID-19/COVID-19.Provider. Update3.17.2020.pdf

22. Maine Department of Health and Human Services. COVID-19 guidance for pharmacies and prescribers. March 26, 2020. Accessed January 30, 2021. https://www1.maine.gov/dhhs/sites/ maine.gov.dhhs/files/documents/ pdfs_doc/COVID-19/COVID-19Guidance-Pharmacies-PrescribersUpdated-03262020.pdf

23. Maryland Department of Health. COVID-19: waiving early refill edits. Maryland Medicaid FFS Program. March 6, 2020. Accessed January 30, 2021. https://health.maryland.gov/mmcp/pap/ docs/Advisory\%20206\%20Waiving\%20 Early\%20Refill\%20Edits.pdf
24. Commonwealth of Massachusetts. Coronavirus disease 2019 (COVID-19) -applicants and members. COVID-19 related information for MassHealth members and applicants. Accessed January 30, 2021. https://www.mass.gov/info-details/ masshealth-coronavirus-disease-2019-covid-19-applicants-and-members

25. The Office of Governor Gretchen Whitmer. Temporary enhancements to operational capacity, flexibility, and efficiency of pharmacies. March 20, 2020. Accessed January 30, 2021. https://www. michigan.gov/whitmer/0,9309,7-38790499 90705-523301--,00.html

26. Minnesota Department of Human Services. DHS allows 90-day supply of prescription maintenance medications for public health care enrollees. April 1, 2020. Accessed January 30, 2021. https:// mn.gov/dhs/people-we-serve/adults/ whats-new/?id=1053-426126

27. NH Department of Health and Human Services. New Hampshire Medicaid Program. July 21, 2020. Accessed January 30, 2021. https://www.dhhs.nh.gov/ ombp/medicaid/documents/covidadmin-protocols.pdf

28. State of New Jersey Department of Human Services. Certificate of Waiver of Medicaid/NJ FamilyCare and Division of Aging Services prescription refill regulations to ensure beneficiary access to medications. March 10, 2020. Accessed January 30, 2021. https://nj.gov/humanservices/ documents/031320FamilyCare\%20.pdf
29. New Mexico Human Services Department. Special COVID-19 Letter of Direction \#7. March 11, 2020. Accessed January 30, 2021. https://nmmedicaid. syst.portal.conduent.com/static/PDFs/ Special\%20COVID-19\%20LOD7\%20 Pharmacy\%20and\%20Waiver\%20of\%20 Signature\%20Requirements.pdf

30. New York State Department of Health. COVID-19 guidance for Medicaid providers. April 6, 2020. Accessed January 30, 2021. https://health.ny.gov/health_care/ medicaid/covid19/2020-03-19_guide_ med pharm.htm

31. North Carolina Medicaid, Division of Health Benefits. Special Bulletin COVID-19 \#2: General guidance and policy modifications. March 13, 2020. Accessed January 30, 2021. https:// medicaid.ncdhhs.gov/blog/2020/03/13/ special-bulletin-covid-19-2-general-guidance-and-policy-modifications

32. North Dakota Human Services. COVID-19 update. April 24, 2020. Accessed January 30, 2021. https:// www.nd.gov/dhs/info/covid-19/docs/ presentation-covid-19-medicaid-services-2020-4-24.pdf

33. Virginia's Medicaid Program. Pharmacy benefit changes in response to COVID-19. August 15, 2020. Accessed January 30, 2021. https://www.virginiamedicaidpharmacyservices.com/ 